\title{
Prognostic significance of tumor budding and single cell invasion in gastric adenocarcinoma
}

\author{
Keying Che ${ }^{1, *}$ \\ Yang Zhao $2,3, *$ \\ Xiao Qu' \\ Zhaofei Pang' \\ Yang $\mathrm{Ni}^{4}$ \\ Tiehong Zhang ${ }^{4}$ \\ Jiajun $\mathrm{Du}^{1,5}$ \\ Hongchang Shen ${ }^{4}$ \\ 'Institute of Oncology, Shandong \\ Provincial Hospital Affiliated \\ to Shandong University, Jinan, \\ ${ }^{2}$ Department of Breast Surgery, Key \\ Laboratory of Breast Cancer in \\ Shanghai, Collaborative Innovation \\ Center of Cancer Medicine, Fudan \\ University Shanghai Cancer Center, \\ ${ }^{3}$ Department of Oncology, Shanghai \\ Medical College, Fudan University, \\ Shanghai, ${ }^{4}$ Department of Oncology, \\ Shandong Provincial Hospital Affiliated \\ to Shandong University, ${ }^{5}$ Department \\ of Thoracic Surgery, Shandong \\ Provincial Hospital Affiliated to \\ Shandong University, Jinan, People's \\ Republic of China \\ *These authors contributed equally \\ to this work
}

\author{
This article was published in the following Dove Press journal: \\ OncoTargets and Therapy \\ 20 February 2017 \\ Number of times this article has been viewed
}

Purpose: Gastric carcinoma (GC) is a highly aggressive cancer and one of the leading causes of cancer-related deaths worldwide. Histopathological evaluation pertaining to invasiveness is likely to provide additional information in relation to patient outcome. In this study, we aimed to evaluate the prognostic significance of tumor budding and single cell invasion in gastric adenocarcinoma.

Materials and methods: Hematoxylin and eosin-stained slides generated from 296 gastric adenocarcinoma patients with full clinical and pathological and follow-up information were systematically reviewed. The patients were grouped on the basis of tumor budding, single cell invasion, large cell invasion, mitotic count, and fibrosis. The association between histopathological parameters, different classification systems, and overall survival (OS) was statistically analyzed.

Results: Among the 296 cases that were analyzed, high-grade tumor budding was observed in $49.0 \%$ (145) of them. Single cell invasion and large cell invasion were observed in $62.8 \%$ (186) and $16.9 \%$ (50) of the cases, respectively. Following univariate analysis, patients with high-grade tumor budding had shorter OS than those with low-grade tumor budding (hazard ratio $[\mathrm{HR}]$ : $2.260, P<0.001)$. Similarly, the OS of patients with single cell invasion and large cell invasion was reduced (single cell invasion, HR: 3.553, $P<0.001$; large cell invasion, HR: $2.466, P<0.001)$. Following multivariate analysis, tumor budding and single cell invasion were observed to be independent risk factors for gastric adenocarcinoma $(P<0.05)$. According to the Lauren classification, patients with intestinal-type adenocarcinoma had better outcomes than those with diffuse-type adenocarcinoma (HR: 2.563, $P<0.001$ ).

Conclusion: Tumor budding and single cell invasion in gastric adenocarcinoma are associated with an unfavorable prognosis.

Keywords: invasion type, pathology, gastric carcinoma, prognosis, metastasis

\section{Introduction}

Gastric carcinoma (GC) is one of the five most frequently occurring cancers in both sexes worldwide. Even though the overall 5-year relative survival rate for GC has increased to $28 \%$ over the past 10 years, the mortality rate remains $>50 \%$ worldwide. ${ }^{1}$ Furthermore, although early-stage patients may experience favorable results after complete resection, some patients may still suffer from metastasis and recurrence., ${ }^{2,3}$ Stage II-III gastric adenocarcinoma patients are treated with multimodality therapy after surgical resection. ${ }^{4-6}$ In order to facilitate optimal clinical management with more favorable outcomes, it is imperative that additional clinicopathological features are used to assess the risk of unfavorable prognosis and to identify individuals who could benefit from personalized therapy after resection. Better and more accurate
Correspondence: Jiajun Du; Hongchang Shen

Shandong Provincial Hospital Affiliated to Shandong University, 324 Jingwu Road, Jinan 25002 I, People's Republic of China $\mathrm{Tel} / \mathrm{fax}+8653168777100$ Email dujiajun568@I63.com; shcl1312@I63.com

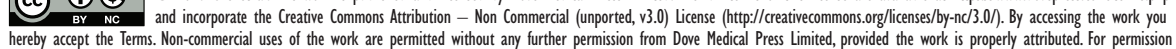
for commercial use of this work, please see paragraphs 4.2 and 5 of our Terms (https://www.dovepress.com/terms.php). 
indicators for prognosis are essential in enabling personalized medicine treatment strategies.

Histomorphological features of gastric cancer have been widely used in the evaluation of patient prognosis. Tumor budding and single cell invasion are two characteristics that have received increasing attention in relation to the invasive front of gastric cancer. Tumor budding is defined as the presence of a cluster of tumor cells, with as many as five cells per cluster at the tumor front. ${ }^{7}$ Single cell invasion refers to the detachment of a single tumor cell from the primary tumor mass at the invasive margin of the tumor. Large cell invasion is defined as invasion by tumor cells whose nuclear diameters are quadruple the size of nearby small lymphocytes. ${ }^{8}$ To date, tumor budding has been recognized to correlate with unfavorable outcomes in patients with many different kinds of carcinomas, including colorectal carcinoma, adenocarcinoma of the lung, laryngeal carcinoma, esophageal carcinoma, and ampullary carcinomas. ${ }^{9-13}$ According to these studies, tumor budding may represent an optimal additional factor, which is helpful for risk stratification in gastric adenocarcinoma. As for the biological significance of tumor budding, investigators have noted that this process may be associated with epithelial-mesenchymal transition (EMT), thereby increasing cancer cell migration and invasion. ${ }^{14,15}$ Tumor budding is considered an indicator of EMT in the tumor microenvironment. It has been suggested that cells associated with tumor budding share similar properties with malignant stem cells. ${ }^{16}$ The Union for International Cancer Control (UICC) has officially recognized tumor budding as an additional independent prognostic factor in colon and rectum carcinomas. ${ }^{17}$ Further studies must be performed to develop a consensus regarding the methods required to evaluate tumor budding and the relationship between these evaluation tools and prognosis in GC.

The aim of the study was to investigate the influence of different invasion types on prognosis and to identify optimal indicators for the outcome of patients with gastric adenocarcinoma.

\section{Materials and methods Selection of patients}

In this study, 296 sequential gastric cancer samples were collected from Shandong Provincial Hospital (affiliated with Shandong University) between 2007 and 2010. The cases were selected sequentially. The following inclusion criteria were used: 1) patients who were pathologically diagnosed with gastric adenocarcinoma, 2) patients whose tumor slides were available for histological evaluation, and 3) patients who had complete follow-up data. The following exclusion criteria were used: 1) patients with previous or attendant other cancers, 2) patients who underwent previous chemotherapy and/or radiation therapy before surgery, and 3) patients whose data were incomplete. All of the 296 cases were followed up for at least 5 years; the total number of cases included 69 female patients and 227 male patients (Table 1). All of the histological slides pertaining to these patients were available for histological evaluation. The tumor subtypes were defined according to the World Health Organization (WHO), Lauren and Goseki classifications. ${ }^{18-20}$ The cases were staged according to the Seventh Edition of the American Joint Committee on Cancer manual. ${ }^{21}$ The clinicopathological characteristics that were assessed included age, sex, tumor-node-metastasis (TNM) classification, pathological stages, degree of tumor differentiation, and smoking or drinking history.

\section{Ethics statement}

The Ethics Committee of Shandong Provincial Hospital approved the study. All of the participants provided written informed consent. All clinical investigations were conducted according to the principles in the Declaration of Helsinki.

\section{Histopathological evaluation}

Histological subtypes of GC were evaluated according to the following three different but commonly used criteria: the WHO classification, the Lauren classification, and the Goseki classification. ${ }^{18-20}$ Each case was evaluated for tumor budding, single cell invasion, large cell invasion, fibrosis, and mitosis. All of the slides were first evaluated at $100 \times$ magnification $(10 \times$ objective lens $)$ to determine the most invasive area. Next, samples were examined at $400 \times$ magnification (40× objective lens). Tumor budding was defined as the presence of small discrete clusters of tumor cells (up to five cells) at the invasive edge or inside the tumor (Figure 1A, 100×, and Figure 1B, 400×). An average of five served as the cut-point of budding in 10 high power fields (HPFs). ${ }^{22}$ High-grade tumor budding was assigned to those cases with $\geq 5$ buds on average. Low-grade tumor budding pertained to those cases that contained, on average, $<5$ buds. Single cell invasion was defined as a single tumor cell within the stromal tissue at the invasive margin of the tumor (Figure 1C). Large cell invasion was defined as invasion by tumor cells whose nuclear diameter was quadruple that of small nearby lymphocytes (Figure 1D). Mitosis was assessed using the cut-point of $10 \mathrm{HPF}$ at $400 \times$ magnification. The average rate of mitosis in $10 \mathrm{HPF}$ is shown in Figure 1E. Fibrosis was evaluated in the $100 \times$ magnification area, and 
Table I Associations between invasion types and clinicopathological characteristics of 296 patients with gastric adenocarcinoma

\begin{tabular}{|c|c|c|c|c|c|c|c|c|c|}
\hline \multirow[t]{2}{*}{ Variables } & \multicolumn{3}{|c|}{ Tumor budding } & \multicolumn{3}{|c|}{ Single cell invasion } & \multicolumn{3}{|c|}{ Large cell invasion } \\
\hline & $(-)$ & $(+)$ & $P$-value & $(-)$ & $(+)$ & $P$-value & $(-)$ & $(+)$ & $P$-value \\
\hline Age (years) & & & 0.362 & & & 0.690 & & & 0.164 \\
\hline$\leq 60$ & $67(22.6 \%)$ & 72 (24.3\%) & & $50(16.9 \%)$ & $89(30.1 \%)$ & & 120 (40.5\%) & $19(6.4 \%)$ & \\
\hline$>60$ & $84(28.4 \%)$ & $73(24.7 \%)$ & & $60(20.3 \%)$ & 97 (32.8\%) & & $126(42.6 \%)$ & $31(10.5 \%)$ & \\
\hline Sex & & & 0.441 & & & 0.640 & & & 0.180 \\
\hline Male & II 3 (38.2\%) & 114 (38.5\%) & & $86(29.1 \%)$ & |4| (47.6\%) & & 185 (62.5\%) & 42 (I4.2\%) & \\
\hline Female & 38 (12.8\%) & $31(10.5 \%)$ & & $24(8.1 \%)$ & 45 (I5.2\%) & & 61 (20.6\%) & $8(2.7 \%)$ & \\
\hline T classification & & & $<0.001$ & & & $<0.001$ & & & 0.005 \\
\hline $\mathrm{TI}+\mathrm{T} 2$ & $63(21.3 \%)$ & $21(7.1 \%)$ & & $55(18.6 \%)$ & $29(9.8 \%)$ & & 78 (26.4\%) & $6(2.0 \%)$ & \\
\hline $\mathrm{T} 3+\mathrm{T} 4$ & 88 (29.7\%) & 124 (4I.9\%) & & 55 (I8.6\%) & 157 (53.0\%) & & 168 (56.8\%) & 44 (I4.9\%) & \\
\hline $\mathrm{N}$ classification & & & $<0.001$ & & & $<0.001$ & & & 0.002 \\
\hline No & $66(22.3 \%)$ & $31(10.5 \%)$ & & $60(20.3 \%)$ & 37 (I2.5\%) & & $90(30.4 \%)$ & 7 (2.4\%) & \\
\hline $\mathrm{NI}+\mathrm{N} 2+\mathrm{N} 3$ & $85(28.7 \%)$ & $114(38.5 \%)$ & & $50(16.9 \%)$ & 149 (50.3\%) & & $156(52.7 \%)$ & $43(14.5 \%)$ & \\
\hline M classification & & & 0.005 & & & 0.001 & & & $<0.001$ \\
\hline Mo & 127 (42.9\%) & $102(34.5 \%)$ & & 97 (32.8\%) & I 32 (44.6\%) & & $20 \mathrm{I}(67.9 \%)$ & $28(9.5 \%)$ & \\
\hline MI & $24(8.1 \%)$ & $43(14.5 \%)$ & & $13(4.4 \%)$ & $54(18.2 \%)$ & & $45(15.2 \%)$ & $22(7.4 \%)$ & \\
\hline Pathological stage & & & $<0.001$ & & & $<0.001$ & & & 0.003 \\
\hline Stage I + II & $77(26.0 \%)$ & $30(10.1 \%)$ & & $68(23.0 \%)$ & $39(13.2 \%)$ & & $98(33.1 \%)$ & $9(3.0 \%)$ & \\
\hline Stage III + IV & $74(25.0 \%)$ & $115(38.9 \%)$ & & 42 (14.2\%) & 147 (49.7\%) & & 148 (50.0\%) & $4 \mathrm{I}(13.9 \%)$ & \\
\hline Tumor differentiation degree & & & $<0.001$ & & & $<0.001$ & & & 0.075 \\
\hline Grade I + I-II & $76(25.7 \%)$ & $123(41.6 \%)$ & & $52(17.6 \%)$ & 147 (49.7\%) & & $160(54.1 \%)$ & $39(13.2 \%)$ & \\
\hline Grade II + III & $75(25.3 \%)$ & $22(7.4 \%)$ & & $58(19.6 \%)$ & $39(13.2 \%)$ & & $86(29.1 \%)$ & II (3.7\%) & \\
\hline Tumor budding & & & & & & $<0.00$ I & & & $<0.001$ \\
\hline$(-)$ & - & - & & $96(32.4 \%)$ & $55(18.6 \%)$ & & 137 (46.3\%) & 14 (4.7\%) & \\
\hline$(+)$ & - & - & & $14(4.7 \%)$ & $|3|(44.3 \%)$ & & $109(36.8 \%)$ & $36(12.2 \%)$ & \\
\hline Large cell invasion & & & $<0.001$ & & & 0.001 & & & \\
\hline$(-)$ & 137 (46.3\%) & $109(36.8 \%)$ & & $102(34.5 \%)$ & I 44 (48.6\%) & & - & - & \\
\hline$(+)$ & 14 (4.7\%) & $36(12.2 \%)$ & & $8(2.7 \%)$ & $42(14.2 \%)$ & & - & - & \\
\hline Single cell invasion & & & $<0.001$ & & & & & & 0.001 \\
\hline$(-)$ & $96(32.4 \%)$ & 14 (4.7\%) & & - & - & & $102(34.5 \%)$ & $8(2.7 \%)$ & \\
\hline$(+)$ & $55(18.6 \%)$ & |3| (44.3\%) & & - & - & & 144 (48.6\%) & $42(14.2 \%)$ & \\
\hline Fibrosis & & & 0.098 & & & 0.321 & & & 0.022 \\
\hline$(+)$ & $63(21.3 \%)$ & $69(23.3 \%)$ & & 47 (I5.9\%) & $85(28.7 \%)$ & & $103(34.8 \%)$ & $29(9.8 \%)$ & \\
\hline$(++)$ & $53(17.9 \%)$ & $55(18.6 \%)$ & & $38(12.8 \%)$ & $70(23.6 \%)$ & & $92(31.1 \%)$ & $16(5.4 \%)$ & \\
\hline$(+++)$ & 35 (11.8\%) & $21(7.1 \%)$ & & $25(8.4 \%)$ & $31(10.5 \%)$ & & $5 \mathrm{I}(17.2 \%)$ & $5(1.7 \%)$ & \\
\hline Mitosis & & & $<0.001$ & & & $<0.001$ & & & $<0.001$ \\
\hline$(-)$ & $100(33.8 \%)$ & $42(14.2 \%)$ & & $83(28.0 \%)$ & $59(19.9 \%)$ & & 133 (44.9\%) & $9(3.0 \%)$ & \\
\hline$(+)$ & $51(17.2 \%)$ & $103(34.8 \%)$ & & $27(9.1 \%)$ & 127 (42.9\%) & & $113(38.2 \%)$ & $4 \mathrm{I}(13.9 \%)$ & \\
\hline Smoking or drinking history & & & 0.993 & & & 0.300 & & & 0.688 \\
\hline Yes & $52(17.6 \%)$ & 50 (16.9\%) & & $42(14.2 \%)$ & $60(20.3 \%)$ & & $86(29.1 \%)$ & 16 (5.4\%) & \\
\hline No & 99 (33.4\%) & 95 (32.1\%) & & $68(23.0 \%)$ & 126 (42.6\%) & & $160(54.1 \%)$ & 34 (II.5\%) & \\
\hline
\end{tabular}

Notes: Degree of tumor differentiation: grade I, poorly differentiated; grade II, moderately and poorly differentiated; grade III, moderately differentiated; IV, well differentiated. $P<0.05$ was considered significant.

Abbreviations: $T$, tumor; $N$, node; $M$, metastasis.

a fibrosis rate of $<30 \%$ was considered "+", $30 \%-60 \%$ as " ++ ", and $>60 \%$ as " $+++"$ (Figure $1 F$ ). All of the slides were initially scanned at $100 \times$ magnification and then assessed at $400 \times$ magnification for accuracy.

\section{Statistical analysis}

Overall survival (OS) was measured from the date of the first definite diagnosis or the date of surgery until the date of death from any cause or the date at which the patient was last known to be alive. Patients with an unknown date of death and patients who died from causes not related to cancer were excluded from this study. Two category comparisons were performed using the chi-square test and Fisher's exact test. Survival curves were plotted according to the Kaplan-Meier method and compared using the log-rank test in a univariate analysis. All of the tests were two sided, and $P$-values $<0.05$ were considered statistically significant. Multivariate analyses using Cox proportional hazards regression model were 

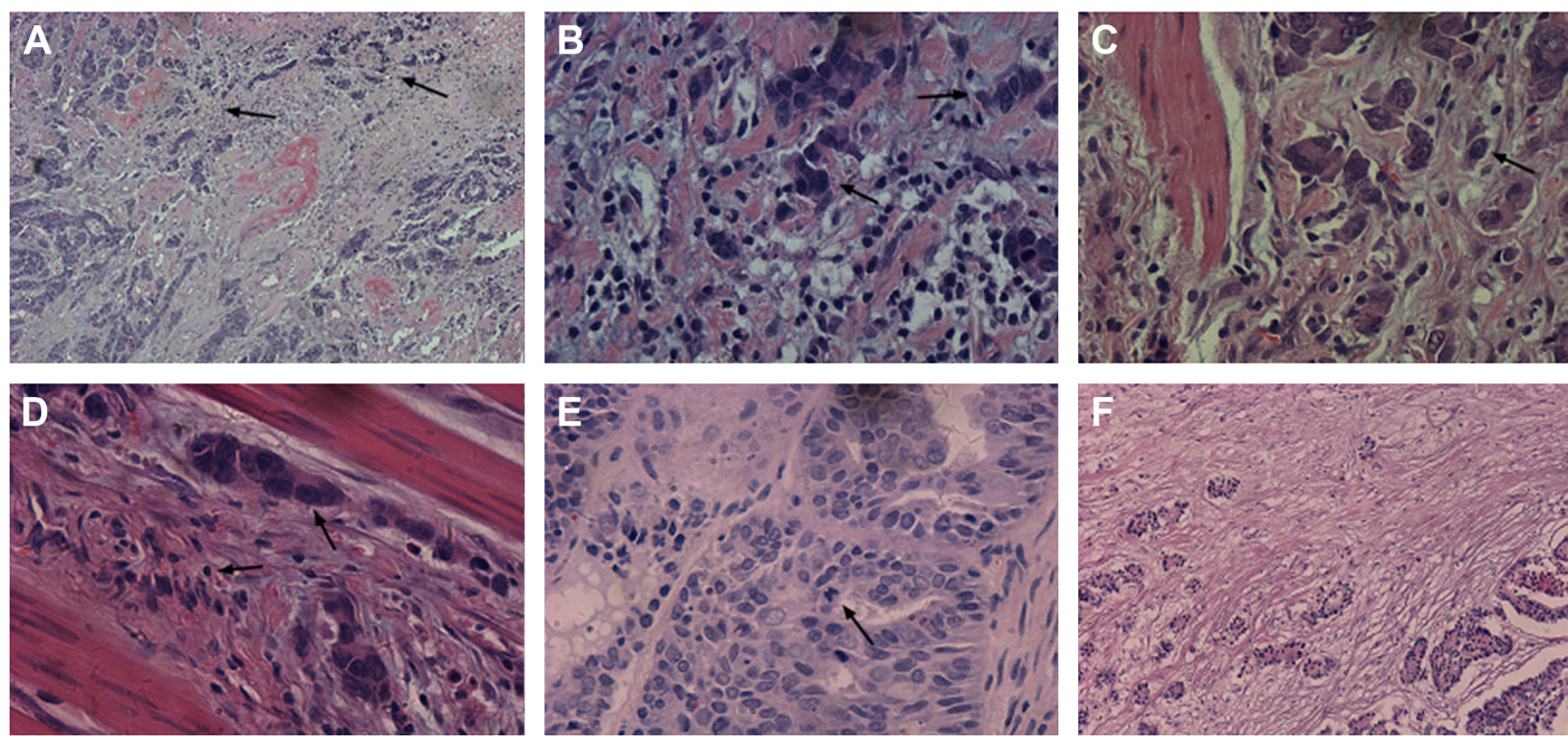

Figure I Microscopic observations for gastric adenocarcinoma (HE stain).

Notes: (A) Tumor budding (arrows) was defined as a cluster of tumor cells composed of fewer than five tumor cells and was evaluated at I00× magnification. (B) Tumor budding (arrows) evaluated at 400× magnification. (C) Single cell invasion indicated by arrows at 400× magnification. (D) Large cell invasion was defined as a tumor cell whose nucleus diameter was quadruple the size of a small nearby lymphocyte. Indicated by arrows at $400 \times$ magnification. (E) Mitosis indicated by arrows at $400 \times$ magnification. (F) Fibrosis was confirmed if the area of fibrosis was $>60 \%$ of the microscopic field. Evaluated at I00 $\times$ magnification.

Abbreviation: $\mathrm{HE}$, hematoxylin and eosin.

performed to determine factors that were independently associated with OS. Statistical analysis was performed using SPSS statistics software version 20.0.

\section{Results}

\section{Associations between invasion types and clinicopathological characteristics}

In this study, 296 patients with gastric adenocarcinoma were assessed. The majority of these patients were male (76.9\%). The association between invasion type and clinicopathological characteristics for the 296 patients with gastric adenocarcinoma is summarized in Table 1. The age of the patients ranged from 23 to 83 years, and the average age was 60 years. Among the analyzed patients, high-grade tumor budding was observed in $49.0 \%$ (145) of the cases. Single cell and large cell invasion incidences were observed in $62.8 \%$ (186) and $16.9 \%$ (50) of the cases, respectively. In this study, $36.1 \%$ (107) of the patients had stage I or II disease, and $63.9 \%$ (189) of the patients had stage III and IV diseases. Among them, $67.2 \%$ (199) of the cases were poorly differentiated or moderately and poorly differentiated, and $32.8 \%$ (97) cases were moderately or well differentiated. Tumor budding, single cell invasion, and large cell invasion were independent of age, sex, and smoking or drinking history $(P>0.05)$. However, the types of invasion were found to significantly correlate with TNM classification, pathological stage, and mitosis $(P<0.05)$. Tumor budding and single cell invasion were significantly associated with the degree of tumor differentiation $(P<0.05)$. A weak association was found between large cell invasion and fibrosis $(P=0.022)$.

\section{Survival analysis}

The univariate analysis of clinical and pathological characteristics is summarized in Table 2. Age, TNM classification, pathological stage, tumor budding, large cell invasion, single cell invasion, mitosis, WHO classification, Lauren classification, Goseki classification, and pathological classification showed statistical significance $(P<0.05)$. Apparently, patients with high-grade tumor budding had shorter OS than those with low-grade tumor budding (hazard ratio [HR]: 2.260, 95\% confidence interval [CI]: 1.617-3.159, $P<0.001$; Figure 2A). Similarly, the OS of patients exhibiting single cell invasion and large cell invasion was reduced (single cell invasion, HR: 3.553, 95\% CI: 2.349-5.374, $P<0.001$, Figure 2B; large cell invasion, HR: $2.466,95 \%$ CI: $1.700-3.578, P<0.001$; Figure $2 \mathrm{C}$ ). Patients whose mitotic counts were $>10 \mathrm{HPF}$ at $400 \times$ magnification had poor prognosis (HR: 1.419, 95\% CI: 1.022-1.971, $P=0.037$; Figure 2D). According to the WHO classification, papillary GC served as the reference, and only the HR of tubular adenocarcinoma showed statistical significance (HR: 0.440, 95\% CI: $0.267-0.726, P=0.001$; Figure $3 \mathrm{~A})$. According to 
Table 2 Univariate Cox regression analysis of clinical and pathological characteristics

\begin{tabular}{|c|c|c|c|}
\hline Variables & HR & $95 \% \mathrm{Cl}$ & $P$-value \\
\hline \multicolumn{4}{|l|}{ Age (years) } \\
\hline$\leq 60$ & 1.000 & Reference & - \\
\hline$>60$ & 1.556 & $1.116-2.168$ & 0.009 \\
\hline \multicolumn{4}{|l|}{ Sex } \\
\hline Male & 1.000 & Reference & - \\
\hline Female & 0.746 & $0.497-1.121$ & 0.159 \\
\hline \multicolumn{4}{|l|}{ T classification } \\
\hline TI & 1.000 & Reference & $<0.001$ \\
\hline $\mathrm{T} 2$ & 5.162 & $1.471-18.117$ & 0.010 \\
\hline $\mathrm{T} 3$ & 10.607 & $3.320-33.886$ & $<0.001$ \\
\hline $\mathrm{T} 4$ & 15.324 & $4.823-48.683$ & $<0.001$ \\
\hline \multicolumn{4}{|l|}{$\mathrm{N}$ classification } \\
\hline No & 1.000 & Reference & $<0.001$ \\
\hline NI & 2.700 & $1.417-5.147$ & 0.003 \\
\hline N2 & 4.234 & $2.426-7.390$ & $<0.001$ \\
\hline N3 & 6.233 & $3.750-10.360$ & $<0.001$ \\
\hline \multicolumn{4}{|l|}{ M classification } \\
\hline MO & 1.000 & Reference & - \\
\hline MI & 2.844 & $2.027-3.989$ & $<0.001$ \\
\hline \multicolumn{4}{|l|}{ Pathological stage } \\
\hline Stage I & 1.000 & Reference & $<0.001$ \\
\hline Stage II & 2.767 & $0.961-7.964$ & 0.059 \\
\hline Stage III & 10.972 & $4.432-27.163$ & $<0.001$ \\
\hline Stage IV & $16.70 \mid$ & $6.666-41.845$ & $<0.001$ \\
\hline \multicolumn{4}{|l|}{ Tumor differentiation degree } \\
\hline Grade I & 1.000 & Reference & 0.110 \\
\hline Grades I-II & 0.729 & $0.484-1.095$ & 0.128 \\
\hline Grade II & 0.690 & $0.470-1.014$ & 0.059 \\
\hline Grade III & 0.228 & $0.032-1.640$ & 0.142 \\
\hline \multicolumn{4}{|l|}{ Tumor budding } \\
\hline$(-)$ & 1.000 & Reference & - \\
\hline$(+)$ & 2.260 & $1.617-3.159$ & $<0.001$ \\
\hline \multicolumn{4}{|l|}{ Large cell invasion } \\
\hline$(-)$ & 1.000 & Reference & - \\
\hline$(+)$ & 2.466 & $1.700-3.578$ & $<0.001$ \\
\hline \multicolumn{4}{|l|}{ Single cell invasion } \\
\hline$(-)$ & 1.000 & Reference & - \\
\hline$(+)$ & 3.553 & $2.349-5.374$ & $<0.001$ \\
\hline \multicolumn{4}{|l|}{ Fibrosis } \\
\hline$(+)$ & 1.000 & Reference & - \\
\hline$(++)$ & 0.767 & $0.538-1.092$ & 0.141 \\
\hline$(+++)$ & 0.517 & $0.315-0.848$ & 0.009 \\
\hline \multicolumn{4}{|l|}{ Mitosis } \\
\hline$(-)$ & 1.000 & Reference & - \\
\hline$(+)$ & 1.419 & $1.022-1.97 \mid$ & 0.037 \\
\hline \multicolumn{4}{|l|}{ Smoking or drinking history } \\
\hline No & 1.000 & Reference & - \\
\hline Yes & 1.350 & $0.969-1.88 \mid$ & 0.076 \\
\hline \multicolumn{4}{|l|}{ WHO classification } \\
\hline Papillary gastric carcinoma & 1.000 & Reference & 0.013 \\
\hline Tubular adenocarcinoma & 0.440 & $0.267-0.726$ & 0.001 \\
\hline Mucinous gastric carcinoma & 0.863 & $0.475-1.567$ & 0.628 \\
\hline Signet ring cell carcinoma & 0.748 & $0.404-1.382$ & 0.353 \\
\hline Low-differentiated adenocarcinoma & 0.844 & $0.485-1.470$ & 0.550 \\
\hline Undifferentiated adenocarcinoma & 1.158 & $1.158-0.739$ & 0.523 \\
\hline
\end{tabular}

Table 2 (Continued)

\begin{tabular}{|c|c|c|c|}
\hline Variables & HR & $95 \% \mathrm{Cl}$ & $P$-value \\
\hline \multicolumn{4}{|c|}{ Lauren classification } \\
\hline Intestinal type & 1.000 & Reference & - \\
\hline Diffuse type & 2.563 & I.789-3.673 & $<0.001$ \\
\hline \multicolumn{4}{|c|}{ Goseki classification } \\
\hline I & 1.000 & Reference & $<0.001$ \\
\hline II & 1.890 & $1.093-3.267$ & 0.023 \\
\hline III & 2.634 & $1.684-4.119$ & $<0.001$ \\
\hline IV & 2.202 & $1.350-3.594$ & 0.002 \\
\hline \multicolumn{4}{|c|}{ Pathological classification } \\
\hline I & 1.000 & Reference & - \\
\hline II & 2.820 & $|.568-5.07|$ & 0.001 \\
\hline III & 3.907 & $2.375-6.425$ & $<0.001$ \\
\hline IV & 6.028 & $3.345-10.865$ & $<0.001$ \\
\hline
\end{tabular}

Abbreviations: $\mathrm{Cl}$, confidence interval; $\mathrm{HR}$, hazard ratio; WHO, World Health Organization; $\mathrm{T}$, tumor; $\mathrm{N}$, node; $\mathrm{M}$, metastasis.

Goseki classification, grades II, III, and IV had HR values of 1.890 (95\% CI: 1.093-3.267, $P=0.023), 2.634$ (95\% CI: 1.684-4.119, $P<0.001$ ), and 2.202 (95\% CI: $1.350-3.594$, $P=0.002)$, respectively. Patients with well-differentiated grades I and II had higher survival rates than those with poorly differentiated grades III and IV (Figure 3C). As in a previous study, diffuse-type patients had unfavorable prognosis (HR: 2.563, 95\% CI: 1.789-3.673, $P<0.001$; Figure 3B). ${ }^{23}$ We observed that patients with the following classification profile (referred to as the "pathological classification" subsequently) were the most suitable for this study: I: patients without tumor budding, single cell invasion, or large cell invasion. II: patients with single cell invasion. III: patients with tumor budding and single cell invasion. IV: patients with tumor budding, single cell invasion, and large cell invasion. The HR values of II, III, and IV were 2.820, 3.907, and 6.028, respectively, and grade I has significant statistical significance with grades II, III, and IV ( $P=0.001, P<0.001$, and $P<0.001$; Figure 3D).

The multivariate analysis of clinical and pathological characteristics is summarized in Table 3. Using the Cox proportional hazards model, the features that showed statistical significance following univariate analysis were further analyzed. The presence of tumor budding, single cell invasion, and large cell invasion was once more observed to unfavorably impact prognosis $(P<0.05)$. Of the variables that were analyzed, tumor budding, single cell invasion, and large cell invasion appeared to have independent effects on OS.

\section{Discussion}

Tumor budding, single cell invasion, and large cell invasion are all important types of tumor invasion. ${ }^{8}$ To date, tumor 

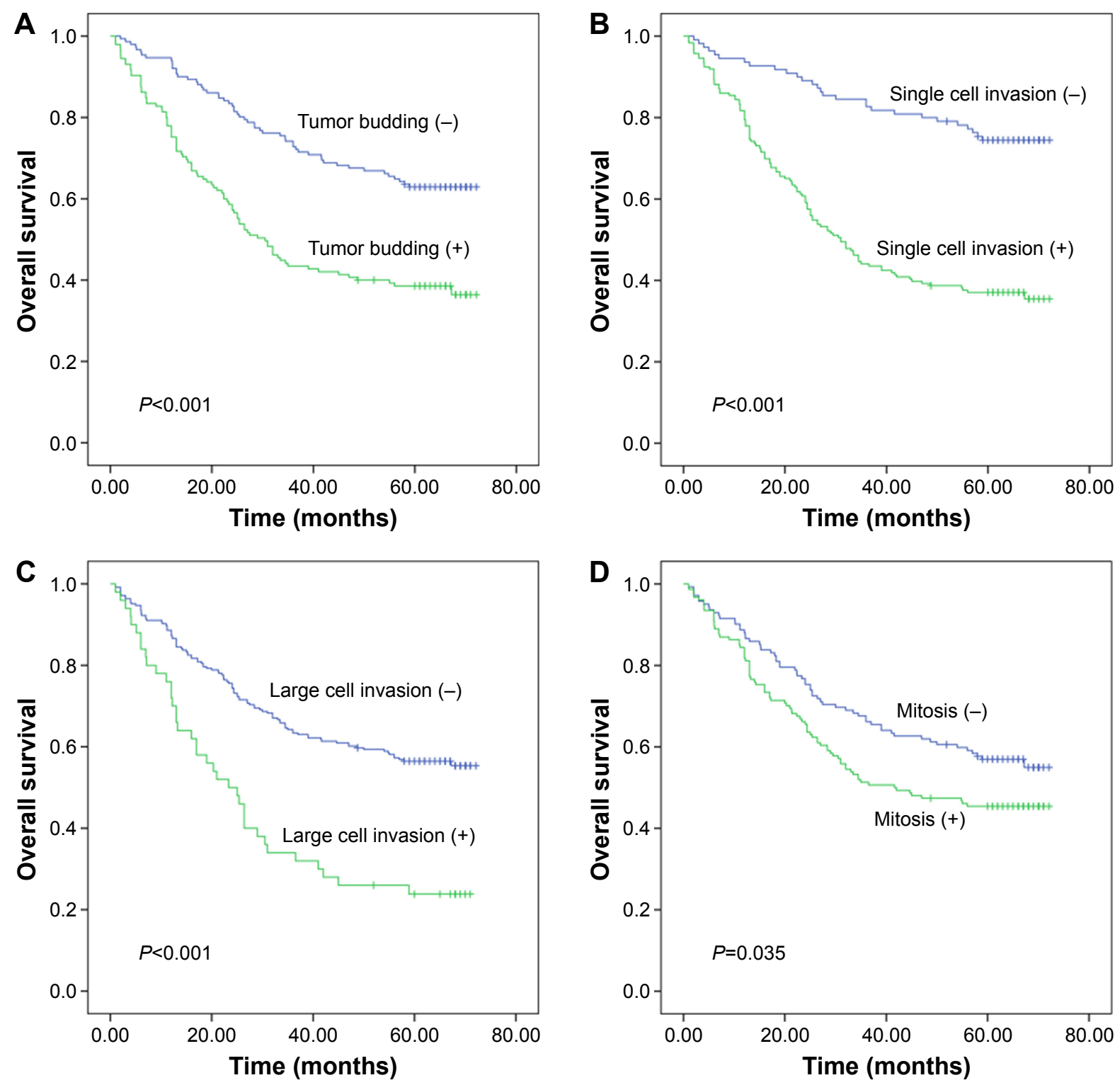

Figure 2 Overall survival (OS) figures pertaining to tumor budding (A), single cell invasion (B), large cell invasion (C), and mitotic count (D) in gastric adenocarcinoma. Notes: (A) Kaplan-Meier survival curve for tumor budding in patients with gastric adenocarcinoma. The OS of cases with high-grade tumor budding was shorter than for cases exhibiting low-grade budding $(P<0.00 \mathrm{I})$. (B) Patients with single cell invasion had shorter OS compared to those without single cell invasion $(P<0.00 \mathrm{I})$. (C) Patients with large cell invasion had shorter OS compared to those without large cell invasion $(P<0.00 \mathrm{I})$. (D) Patients with high mitotic count had shorter OS compared to those without high mitotic count $(P=0.035)$.

budding has been shown to correlate with unfavorable prognosis in many malignant carcinomas, such as colorectal cancer, pancreatic ductal adenocarcinoma, tongue squamous cell carcinoma, and gingival buccal complex squamous cell carcinoma. ${ }^{10,24-26}$ However, research is urgently required to analyze tumor budding in GC. It is speculated that tumor budding may be an important indicator of outcomes, providing a diagnostic guide to facilitate individual treatment in the future. In addition, the mechanisms by which tumor budding exerts effects on the metastasis and invasiveness of tumors merit further study.
EMT is a process by which cells switch from an epithelial to a mesenchymal phenotype. ${ }^{27}$ The epithelial cells develop enhanced motility and show a fibroblast-like morphology. During review of the cases pertaining to the current work, tumor budding was not only observed in the area of the invasive front, where it has been previously described, but also in the tumor itself. This discovery suggests that tumor budding is involved in the EMT that takes place when buds cross the tumor body with the help of rich tumor stroma. The finding that single cell infiltration was associated with poor prognosis is also likely to be reflective of the mechanisms 

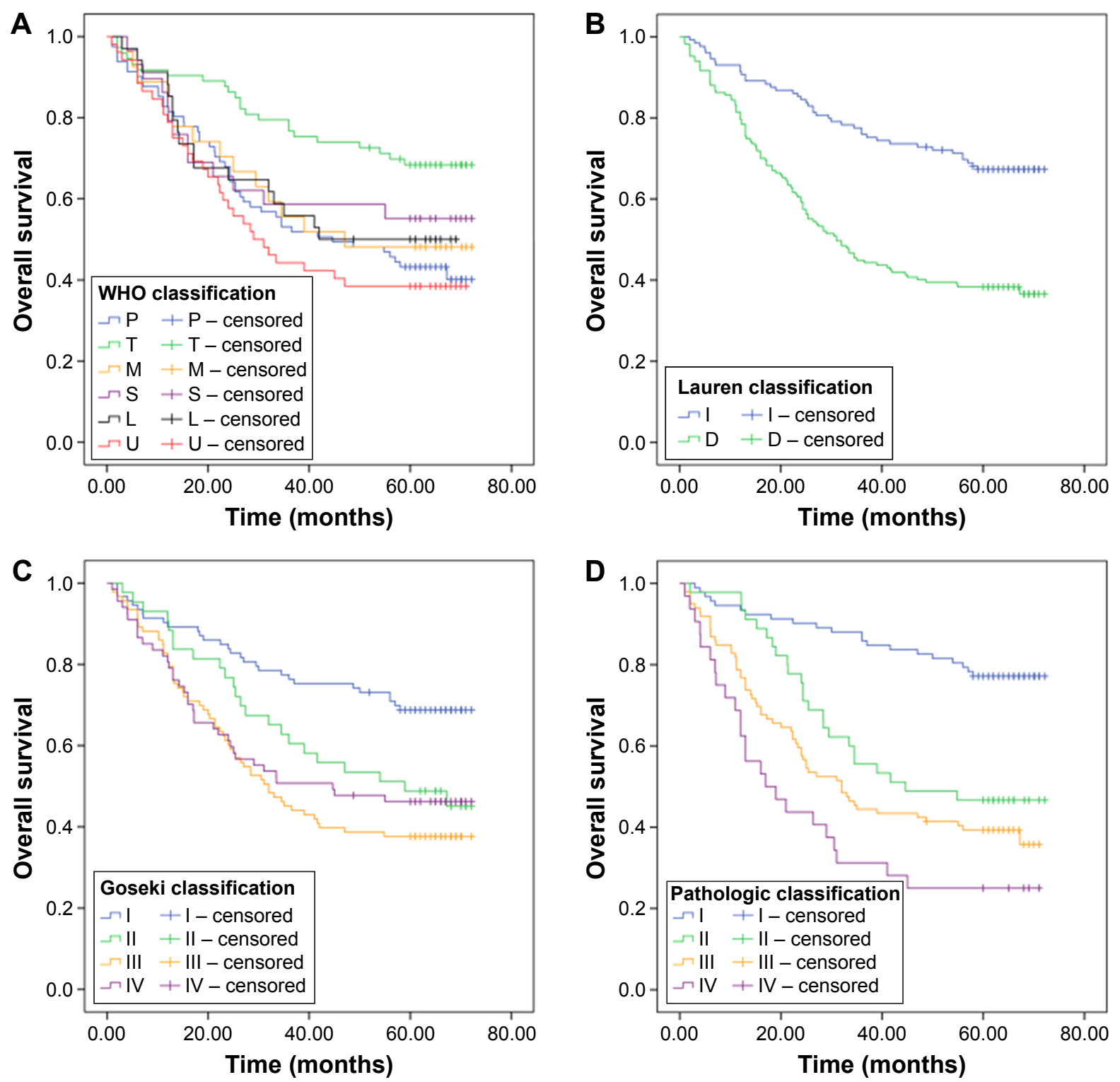

Figure 3 Survival curves according to different classification systems in gastric adenocarcinoma.

Notes: (A) Kaplan-Meier survival curve of WHO classification in patients with gastric adenocarcinoma. Papillary carcinoma showed statistically significant differences with tubular carcinoma subtype $(P=0.00 \mathrm{I})$ but not with other subtypes (mucinous carcinoma, $P=0.628$; signet ring cell carcinoma, $P=0.353$; low-differentiated carcinoma, $P=0.550$; and undifferentiated carcinoma, $P=0.528$ ). $P, T, M, S, L$, and $U$ represent papillary carcinoma, tubular carcinoma, mucinous carcinoma, signet ring cell carcinoma, minimally differentiated carcinoma, and undifferentiated carcinoma, respectively. (B) According to the Lauren classification, diffuse-type patients have unfavorable prognosis $(P<0.00 \mathrm{I})$. I and D represent intestinal-type and diffuse-type gastric adenocarcinoma, respectively. (C) According to the Gosrki classification, the well-differentiated grades I and II had higher survival rates than the poorly differentiated grades III and IV. Grade I showed statistically significant differences compared with grades II, III, and IV ( $P=0.023, P<0.00$ I, and $P=0.002$ ). I: well-differentiated and mucin-poor areas of tumor. II: well-differentiated and mucin-rich parts of the tumor. III: poorly differentiated and mucin-poor parts of the tumor. IV: poorly differentiated and mucin-rich parts of the tumor. (D) According to the new pathological classification, grade I showed statistically significant difference from grades II, III, and IV ( $P=0.00 \mathrm{I}, P<0.00 \mathrm{I}$, and $P<0.00 \mathrm{I})$. I: patients without tumor budding, single cell invasion, and large cell invasion. II: patients with single cell invasion. III: patients with tumor budding and single cell invasion. IV: patients with tumor budding, single cell invasion, and large cell invasion.

Abbreviation: WHO, World Health Organization.

that underpin metastasis. Tumor dissociation and single tumor cells may metastasize to distant organs through the lymph vessels or blood vessels. As a consequence, metastasis of malignant carcinoma can occur following mesenchymalepithelial transition. This phenomenon may also suggest that tumor cells in buds exhibit characteristics that are synonymous with stem cells. ${ }^{16}$ This is highly relevant considering that, in the near future, developing technology may allow for an increasing number of gastric cancers to be diagnosed following preoperative biopsy of tissue that does not contain the invasive front.

In this study, we speculate that the isolated single tumor cells that were observed to be detached from the primary tumor can be regarded as anoikis-resistant cells. The single 
Table 3 Multivariate Cox regression analysis of clinical and pathological characteristics

\begin{tabular}{|c|c|c|c|c|}
\hline Factors & Category & HR & $95 \% \mathrm{Cl}$ & $P$-value \\
\hline \multicolumn{5}{|c|}{ Model for tumor budding } \\
\hline \multirow[t]{2}{*}{ Age (years) } & $\leq 60$ & 1.000 & Reference & - \\
\hline & $>60$ & 1.578 & $|| .2|-2.22|$ & 0.009 \\
\hline \multirow[t]{2}{*}{ Large cell invasion } & $(-)$ & 1.000 & Reference & - \\
\hline & $(+)$ & 1.566 & $1.05 \mathrm{I}-2.333$ & 0.028 \\
\hline \multirow[t]{2}{*}{ Tumor budding } & $(-)$ & 1.000 & Reference & - \\
\hline & $(+)$ & 1.568 & $1.044-2.354$ & 0.030 \\
\hline \multirow[t]{2}{*}{ Mitosis } & $(-)$ & 1.000 & Reference & - \\
\hline & $(+)$ & 0.878 & $0.611-1.263$ & 0.484 \\
\hline \multirow[t]{4}{*}{ Pathological stage } & I & 1.000 & Reference & - \\
\hline & II & 2.280 & $0.786-6.616$ & 0.129 \\
\hline & III & 8.855 & $3.514-22.317$ & $<0.001$ \\
\hline & IV & 12.699 & $4.959-32.520$ & $<0.001$ \\
\hline Tumor differentiation & Grade I & 1.000 & Reference & - \\
\hline \multirow[t]{3}{*}{ degree } & Grades I-II & 0.827 & $0.54 \mid-1.264$ & 0.380 \\
\hline & Grade II & 1.146 & $0.726-1.810$ & 0.557 \\
\hline & Grade III & 0.639 & $0.085-4.794$ & 0.663 \\
\hline \multicolumn{5}{|c|}{ Model of single cell invasion } \\
\hline \multirow[t]{2}{*}{ Age (years) } & $\leq 60$ & 1.000 & Reference & - \\
\hline & $>60$ & 1.677 & $1.192-2.358$ & 0.003 \\
\hline \multirow[t]{2}{*}{ Large cell invasion } & $(-)$ & 1.000 & Reference & - \\
\hline & $(+)$ & 1.699 & $1.145-2.522$ & 0.008 \\
\hline \multirow[t]{2}{*}{ Single cell invasion } & $(-)$ & 1.000 & Reference & - \\
\hline & $(+)$ & 2.385 & I.562-3.787 & $<0.001$ \\
\hline \multirow[t]{2}{*}{ Mitosis } & $(-)$ & 1.000 & Reference & - \\
\hline & $(+)$ & 0.789 & $0.547-1.136$ & 0.203 \\
\hline \multirow[t]{4}{*}{ Pathological stage } & I & 1.000 & Reference & - \\
\hline & II & 2.068 & $0.708-6.038$ & 0.184 \\
\hline & III & 7.237 & $2.846-|8.40|$ & $<0.001$ \\
\hline & IV & 10.259 & $3.962-26.564$ & $<0.001$ \\
\hline Tumor differentiation & Grade I & 1.000 & Reference & - \\
\hline \multirow[t]{3}{*}{ degree } & Grades I-II & 0.802 & $0.530-1.215$ & 0.298 \\
\hline & Grade II & $\mathrm{I} .144$ & $0.752-1.740$ & 0.529 \\
\hline & Grade III & 0.712 & $0.095-5.354$ & $0.74 \mid$ \\
\hline
\end{tabular}

Abbreviations: $\mathrm{Cl}$, confidence interval; $\mathrm{HR}$, hazard ratio.

tumor cells exhibit similar characteristics of invasiveness and metastasis as malignant carcinoma. In normal epithelial cells, loss of cell-cell or cell-matrix interactions triggers a form of apoptosis known as anoikis, which inhibits the survival of cancer cells in circulation. ${ }^{28}$ However, anoikis-resistant cells can resist anoikis and survive in the blood or lymph, finally establishing secondary tumors. These anoikis-resistant tumor cells play an important role in the complex process of tumor metastasis. One study explored the role of EMT in anoikisresistant human lung cancer cells. ${ }^{29}$ As a part of the tumor metastasis mechanism, the complex relationship between EMT and anoikis-resistance merits further exploration.

According to the results generated in the current study, histological subtypes of GC are associated with prognosis. The Lauren classification is a means of classifying biological behaviors and was proposed several decades ago. Upon analysis using this system, we observed that patients with intestinal-type gastric cancer have more favorable outcomes than patients with diffuse-type gastric cancer (Table 2). In addition, the Goseki classification system, which is based on the differentiation and quantity of tumor cell mucus of the carcinoma, has statistical significance when it comes to predicting prognosis. The well-differentiated I and II subtypes exhibit longer OS than the III and IV subtypes with poor differentiation..$^{20,30}$ However, poor-mucus grade III cases have poorer prognosis compared with rich-mucus grade III cases. In this study, not all of the histological subtypes pertaining to the WHO classification displayed statistically significant differences, and tubular carcinoma resulted in better prognosis than papillary carcinoma; these findings are not consistent with the findings of a previous study. ${ }^{18}$ Based on the results of this study, we observed that the WHO classification is not suitable for Asian or Chinese individuals with gastric adenocarcinoma; this is why additional classification systems were deployed during this study. Furthermore, we propose that a new set of criteria for histomorphological evaluation and classification in relation to gastric adenocarcinoma should be established to facilitate more accurate estimates. However, classification systems including Lauren classification can still be useful in estimating prognosis and guiding the choice of therapeutic regimens that are utilized. Results showed that tumor invasion types can influence the prognosis of gastric adenocarcinoma. Thus, a new histological classification system pertaining to tumor invasion types should be established to help evaluate prognosis and aid in risk stratification.

The impact of tumor invasion types in the early-stage subgroup has yet to be studied in preoperative biopsy specimens. The current study may be limited by the relatively small number of gastric adenocarcinoma patients and the fact that all cases come from a single center. However, the study benefits from complete clinical-pathological data with information regarding adjuvant therapy and follow-up. Multicenter research covering a larger number of patients should be analyzed and may provide more evidence for the significance of tumor invasion types.

\section{Conclusion}

According to the current work, tumor budding and single cell invasion should be recognized as useful microscopic indicators that are reflective of biological activity of the tumor. These indicators will hopefully help to better stratify GC patients into subgroups, thereby leading to better clinical decision making in terms of intraoperative or postoperative treatment choices. 


\section{Acknowledgments}

The work was supported by Provincial science and technology development plan of Shandong (2015GSF118129) and National Natural Science Foundation of China (project 81301728). We are extremely grateful to all the patients and to everyone who helped complete this research successfully.

\section{Author contributions}

All authors contributed toward data analysis, drafting and critically revising the paper and agree to be accountable for all aspects of the work.

\section{Disclosure}

All authors report no conflicts of interest in this work.

\section{References}

1. Siegel R, Naishadham D, Jemal A. Cancer statistics, 2013. CA Cancer J Clin. 2013;63(1):11-30.

2. Macdonald JS, Smalley SR, Benedetti J, et al. Chemoradiotherapy after surgery compared with surgery alone for adenocarcinoma of the stomach or gastroesophageal junction. N Engl J Med. 2001;345(10):725-730.

3. Ito $\mathrm{H}$, Inoue $\mathrm{H}$, Ikeda $\mathrm{H}$, et al. Clinicopathological characteristics and treatment strategies in early gastric cancer: a retrospective cohort study. J Exp Clin Cancer Res. 2011;30:117.

4. Glynne-Jones R, Nilsson PJ, Aschele C, et al. Anal cancer: ESMOESSO-ESTRO clinical practice guidelines for diagnosis, treatment and follow-up. Radiother Oncol. 2014;111(3):330-339.

5. Ajani JA, Eisenberg B, Emanuel P, et al. NCCN practice guidelines for upper gastrointestinal carcinomas. Oncology. 1998;12(11 A):179-223.

6. Strong VE, D'Amico TA, Kleinberg L, Ajani J. Impact of the 7th edition AJCC staging classification on the NCCN clinical practice guidelines in oncology for gastric and esophageal cancers. J Natl Compr Canc Netw. 2013;11(1):60-66.

7. Koelzer VH, Langer R, Zlobec I, Lugli A. Tumor budding in upper gastrointestinal carcinomas. Front Oncol. 2014;4:216

8. Zhao Y, Shen H, Qiu C, et al. Invasion types are associated with poor prognosis in lung squamous carcinoma patients. Medicine. 2015; 94(43):e1634.

9. Yamaguchi Y, Ishii G, Kojima M, et al. Histopathologic features of the tumor budding in adenocarcinoma of the lung: tumor budding as an index to predict the potential aggressiveness. J Thorac Oncol. 2010;5(9): 1361-1368.

10. Mitrovic B, Schaeffer DF, Riddell RH, Kirsch R. Tumor budding in colorectal carcinoma: time to take notice. Mod Pathol. 2012;25(10): 1315-1325.

11. Sarioglu S, Acara C, Akman FC, et al; for Dokuz Eylül Head and Neck Tumour Group (DEHNTG). Tumor budding as a prognostic marker in laryngeal carcinoma. Pathol Res Pract. 2010;206(2):88-92.

12. Ohike N, Coban I, Kim GE, et al. Tumor budding as a strong prognostic indicator in invasive ampullary adenocarcinomas. Am J Surg Pathol. 2010;34(10):1417-1424.

OncoTargets and Therapy

\section{Publish your work in this journal}

OncoTargets and Therapy is an international, peer-reviewed, open access journal focusing on the pathological basis of all cancers, potential targets for therapy and treatment protocols employed to improve the management of cancer patients. The journal also focuses on the impact of management programs and new therapeutic agents and protocols on
13. Brown M, Sillah K, Griffiths EA, et al. Tumour budding and a low host inflammatory response are associated with a poor prognosis in oesophageal and gastro-oesophageal junction cancers. Histopathology. 2010;56(7):893-899.

14. De Craene B, Berx G. Regulatory networks defining EMT during cancer initiation and progression. Nat Rev Cancer. 2013;13(2):97-110.

15. Zlobec I, Lugli A. Epithelial mesenchymal transition and tumor budding in aggressive colorectal cancer: tumor budding as oncotarget. Oncotarget. 2010;1(7):651-661.

16. Brabletz T, Jung A, Spaderna S, Hlubek F, Kirchner T. Opinion: migrating cancer stem cells - an integrated concept of malignant tumour progression. Nat Rev Cancer. 2005;5(9):744-749.

17. Vieth M, Quirke P, Lambert R, von Karsa L, Risio M. European guidelines for quality assurance in colorectal cancer screening and diagnosis. First Edition - annotations of colorectal lesions. Endoscopy. 2012;44(suppl 3):Se131-Se139.

18. Flejou JF. Classification OMS 2010 des tumeurs digestives: la quatrième édition [WHO classification of digestive tumors: the fourth edition]. Ann Pathol. 2011;31(5 suppl):S27-S31. French.

19. Lauren $P$. The two histological main types of gastric carcinoma: diffuse and so-called intestinal-type carcinoma. An attempt at a histo-clinical classification. Acta Pathol Microbiol Scand. 1965;64:31-49.

20. Goseki N, Takizawa T, Koike M. Differences in the mode of the extension of gastric cancer classified by histological type: new histological classification of gastric carcinoma. Gut. 1992;33(5):606-612.

21. Edge SB, Compton CC. The American Joint Committee on Cancer: the 7th edition of the AJCC cancer staging manual and the future of TNM. Ann Surg Oncol. 2010;17(6):1471-1474.

22. Ueno H, Mochizuki $H$, Hashiguchi $Y$, et al. Risk factors for an adverse outcome in early invasive colorectal carcinoma. Gastroenterology. 2004;127(2):385-394.

23. Werner M, Becker KF, Keller G, Hofler H. Gastric adenocarcinoma: pathomorphology and molecular pathology. J Cancer Res Clin Oncol. 2001;127(4):207-216.

24. Wang C, Huang $\mathrm{H}$, Huang Z, et al. Tumor budding correlates with poor prognosis and epithelial-mesenchymal transition in tongue squamous cell carcinoma. J Oral Pathol Med. 2011;40(7):545-551.

25. O'Connor $\mathrm{K}$, Li-Chang HH, Kalloger SE, et al. Tumor budding is an independent adverse prognostic factor in pancreatic ductal adenocarcinoma. Am J Surg Pathol. 2015;39(4):472-478.

26. Manjula BV, Augustine S, Selvam S, Mohan AM. Prognostic and predictive factors in gingivo buccal complex squamous cell carcinoma: role of tumor budding and pattern of invasion. Indian J Otolaryngol Head Neck Surg. 2015;67(suppl 1):98-104.

27. Tanabe S, Aoyagi K, Yokozaki H, Sasaki H. Regulated genes in mesenchymal stem cells and gastric cancer. World J Stem Cells. 2015; 7(1):208-222.

28. Liotta LA, Kohn E. Anoikis: cancer and the homeless cell. Nature. 2004;430(7003):973-974.

29. Winitthana T, Lawanprasert S, Chanvorachote P. Triclosan potentiates epithelial-to-mesenchymal transition in anoikis-resistant human lung cancer cells. PLoS One. 2014;9(10):e110851.

30. Calik M, Calik I, Demirci E, et al. Goseki grade and tumour location influence survival of patients with gastric cancer. Asian Pac J Cancer Prev. 2014;15(3):1429-1434

patient perspectives such as quality of life, adherence and satisfaction The manuscript management system is completely online and includes a very quick and fair peer-review system, which is all easy to use. Visit http://www.dovepress.com/testimonials.php to read real quotes from published authors. 